\title{
Rating the incidence of iatrogenic vascular injuries in thoracic and lumbar spine surgery as regards the approach: A PRISMA-based literature review
}

\author{
Alice Giotta Lucifero ${ }^{1}$ Cristian Gragnaniello ${ }^{2}$ Matias Baldoncini ${ }^{3}$ - Alvaro Campero ${ }^{4,5} \cdot$ Gabriele Savioli $^{6,7}$. \\ Nicola Tartaglia ${ }^{8} \cdot$ Antonio Ambrosi $^{8} \cdot$ Sabino Luzzi ${ }^{1,9}$
}

Received: 26 April 2021 / Revised: 2 August 2021 / Accepted: 6 August 2021 / Published online: 19 August 2021

(c) The Author(s) 2021

\begin{abstract}
Purpose To assess the rate, timing of diagnosis, and repairing strategies of vascular injuries in thoracic and lumbar spine surgery as their relationship to the approach.

Methods PubMed, Medline, and Embase databases were utilized for a comprehensive literature search based on keywords and mesh terms to find articles reporting iatrogenic vascular injury during thoracic and lumbar spine surgery. English articles published in the last ten years were selected. The search was refined based on best match and relevance.

Results Fifty-six articles were eligible, for a cumulative volume of 261 lesions. Vascular injuries occurred in $82 \%$ of instrumented procedures and in 59\% during anterior approaches. The common iliac vein (CIV) was the most involved vessel, injured in $49 \%$ of anterior lumbar approaches. Common iliac artery, CIV, and aorta were affected in $40 \%, 28 \%$, and $28 \%$ of posterior approaches, respectively. Segmental arteries were injured in $68 \%$ of lateral approaches. Direct vessel laceration occurred in $81 \%$ of cases and recognized intraoperatively in $39 \%$ of cases.

Conclusions Incidence of iatrogenic vascular injuries during thoracic and lumbar spine surgery is low but associated with an overall mortality rate up to $65 \%$, of which less than $1 \%$ for anterior approaches and more than $50 \%$ for posterior ones. Anterior approaches for instrumented procedures are at risk of direct avulsion of CIV. Posterior instrumented fusions are at risk for injuries of iliac vessels and aorta. Lateral routes are frequently associated with lesions of segmental vessels. Suture repair and endovascular techniques are useful in the management of these severe complications.
\end{abstract}

Keywords Aorta $\cdot$ Common iliac vein $\cdot$ Iatrogenic vascular injury $\cdot$ Inferior vena cava $\cdot$ Instrumented spine surgery $\cdot$ Spine surgery $\cdot$ Vascular injuries

Sabino Luzzi

sabino.luzzi@unipv.it

1 Department of Clinical-Surgical, Diagnostic and Pediatric Sciences, Neurosurgery Unit, University of Pavia, Polo Didattico "Cesare Brusotti", Viale Brambilla, 74, 27100 Pavia, Italy

2 Department of Neurological Surgery, University of Illinois at Chicago, Il 1200 W Harrison St, Chicago, IL 60607, USA

3 Laboratory of Neuroanatomic Microsurgical-LaNeMic-II Division of Anatomy, School of Medicine, University of Buenos Aires, CABA C1053, Buenos Aires, Argentina

4 LINT, Facultad de Medicina, Universidad Nacional de Tucumán, T4000 Tucumán, Argentina
5 Department of Neurological Surgery, Hospital Padilla, T4000 Tucumán, Argentina

6 Emergency Department, Fondazione IRCCS Policlinico San Matteo, Viale C. Golgi, 19, 27100 Pavia, Italy

7 PhD School in Experimental Medicine, Department of Clinical-Surgical, Diagnostic and Pediatric Sciences, University of Pavia Polo Didattico "Cesare Brusotti”, Viale Brambilla, 74, 27100 Pavia, Italy

8 Department of Medical and Surgical Sciences, University of Foggia, Italy Via A.Gramsci 89/91, 71100 Foggia, Italy

9 Department of Surgical Sciences, Neurosurgery Unit, Fondazione IRCCS Policlinico San Matteo, Viale C. Golgi, 19, 27100 Pavia, Italy 


\section{Introduction}

Vascular injuries are rare but potentially life-threatening complications in thoracic and lumbar spinal surgery, having a reported incidence of $0.01 \%$ to $1 \%$, and variable overall mortality that ranges between 15 and $65 \%$ [1-3].

The widening of the spectrum of the surgical corridors for the treatment of spinal diseases, frequently involving the dissection and mobilization of the major splanchnic vessels, has increased the risk of vascular injuries [4-7]. The occurrence of vascular lesions is related to the proximity of the thoracic and lumbar column to the retroperitoneal vascular structures, separated from the latter uniquely by the anterior longitudinal ligament $[8,9]$.

Clinical presentation is not always easily recognized, especially when the injury is related to a posterior approach. Several factors as the type of approach, vessel's caliper, and mechanism of injury complicate the patient's presentation and recognition of the injury. Direct damages, as arterial or venous laceration, generally lead to an acute retroperitoneal hemorrhage with abdominal distention, hypotension, and hematocrit drop [10, 11]. Conversely, delayed injuries can occur days, weeks, or even months following the procedure. They are characterized by a widening of the arterial pressure and tachycardia, which are possibly related formation of thrombi, pseudoaneurysms, or arteriovenous fistulas [12-16]. One difficulty to recognize the cause of delayed vascular injury relates to progressive damage to the vessel wall by prominent hardware [17-21].

A prompt diagnosis, adequate intraoperative management, and early repair are paramount to prevent devastating sequelae.

Nevertheless, literature about the incidence, recognition, and treatment of vascular injuries during thoracic and lumbar spine approaches is still limited, which contributes to a potential underestimation of the overall complication rate of this type of surgery.

The present study consists of a literature review on vascular complications of thoracolumbar spine surgery aimed to infer whether or not potential links do exist between the type of surgical approach, mechanism of injury, and type of injured vessel. Repair strategies and overall outcomes are also discussed.

\section{Materials and methods}

An online literature search was conducted on PubMed/ MEDLINE and Embase search engines with combinations of Medical Subject Heading (MeSH) (PubMed) terms and text words. A Population, Intervention, Comparison, Outcome (PICO) search strategy was employed. The MeSH terms "thoracic spinal surgery" [MeSH], "lumbar spinal surgery" $[\mathrm{MeSH}]$, "anterior lumbar interbody fusion" [MeSH], "posterior lumbar interbody fusion" [MeSH], "lateral lumbar interbody fusion" [MeSH], "lumbar disc surgery" $[\mathrm{MeSH}]$ were combined with "vascular injury" [text word], "iatrogenic vascular injury" [text word], "vessel laceration" [text word], "thrombosis" [text word], "arteriovenous fistula" [text word], "pseudoaneurysm" [text word].

Clinical trials, reviews, cohort studies, and case reports in English or translated to English language and published in the last 10 years were selected. The relevance of each article about the primary endpoint of the study was established by three different independent researchers based on the match with the search terms. Apart from the match, relevance, and years, no further restriction criteria were applied. Overall data about the vascular injuries were extracted, and a descriptive analysis was performed.

\section{Results}

\section{Literature volume}

The literature search initially returned a total of 134 articles. After the removal of duplicates, 74 articles were assessed for eligibility. The application of the exclusion criteria led to the selection of 56 relevant articles for quantitative and qualitative analysis. Non-English articles excluded from the review amounted to 12 . The overall level of evidence of the literature volume according to Strength of Recommendation Taxonomy (SORT) [22] has been low and consisting of 38 case reports $(68 \%)$ and 18 retrospective case series (32\%).

Studies concerning the anterior, posterior lateral approaches to thoracic and lumbar spinal pathologies were 38,11 , and 7 , respectively. Figure 1 reports the PRISMA flowchart of the study (Fig. 1).

\section{Demographic and clinical data}

A total of 261 patients from 56 studies were included. Patients' average age in the anterior, posterior, and lateral groups was $52.6 \pm 11,48 \pm 15$, and $57.5 \pm 12$ years old, respectively. The fifth decade was the more affected.

Tables 1,2, and 3 summarize the main demographic and clinical data of the anterior, posterior, and lateral groups, respectively (Tables 1, 2, and 3). 


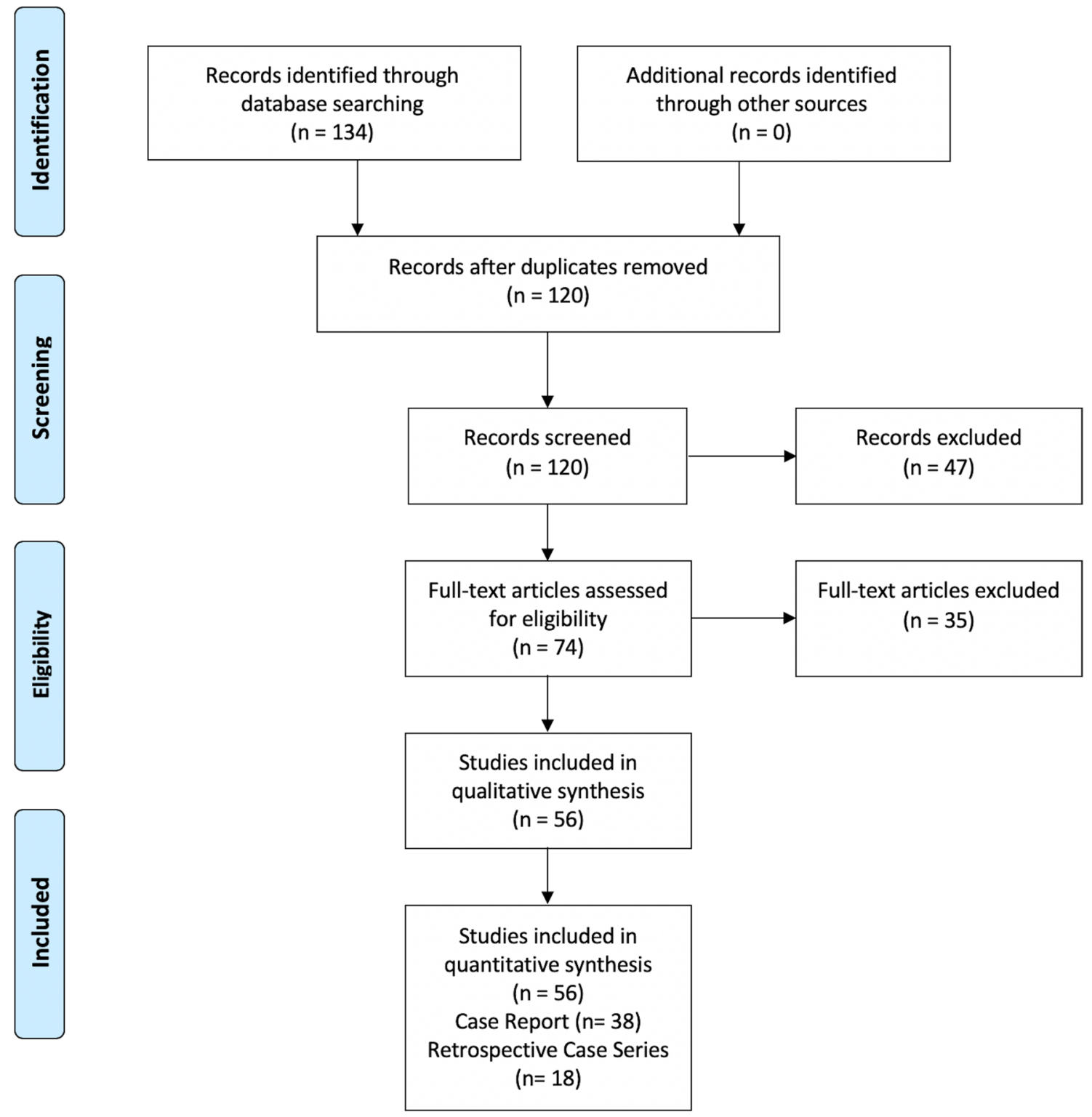

Fig. 1 PRISMA flowchart of the study

\section{Frequency of primary diseases}

Spondylolisthesis was the indication for surgery in 87 cases (34\%), followed by degenerative disc disease $(24 \%)$, disc herniation (16\%), scoliosis (11\%), and fractures (6\%). Less common diseases were osteomyelitis (4\%), pseudarthrosis (3\%), and spinal stenosis (2\%) (Fig. 2).

\section{Type of procedures}

In 208 cases ( $82 \%$ ), an instrumented thoracic or lumbar spinal surgery was performed. In the remaining cases, a discectomy, corpectomy, or osteophytectomy were carried out.

\section{Operative levels}

L4-L5 was the most affected level as it was involved 220 cases (12\%), followed by L5-S1 (10\%), L3-L4 (9\%), L2-L3 (8\%), and L1-L2 (7\%), in this order of frequency. About the thoracic spine, no prevalence between the affected levels was observed (Fig. 3).

\section{Surgical approaches}

One hundred and fifty-four patients (59\%) underwent an anterior approach, of which 86 consisted of an anterior lumbar interbody fusion (ALIF). A posterior approach was performed in 85 (33\%) patients, and a posterior 


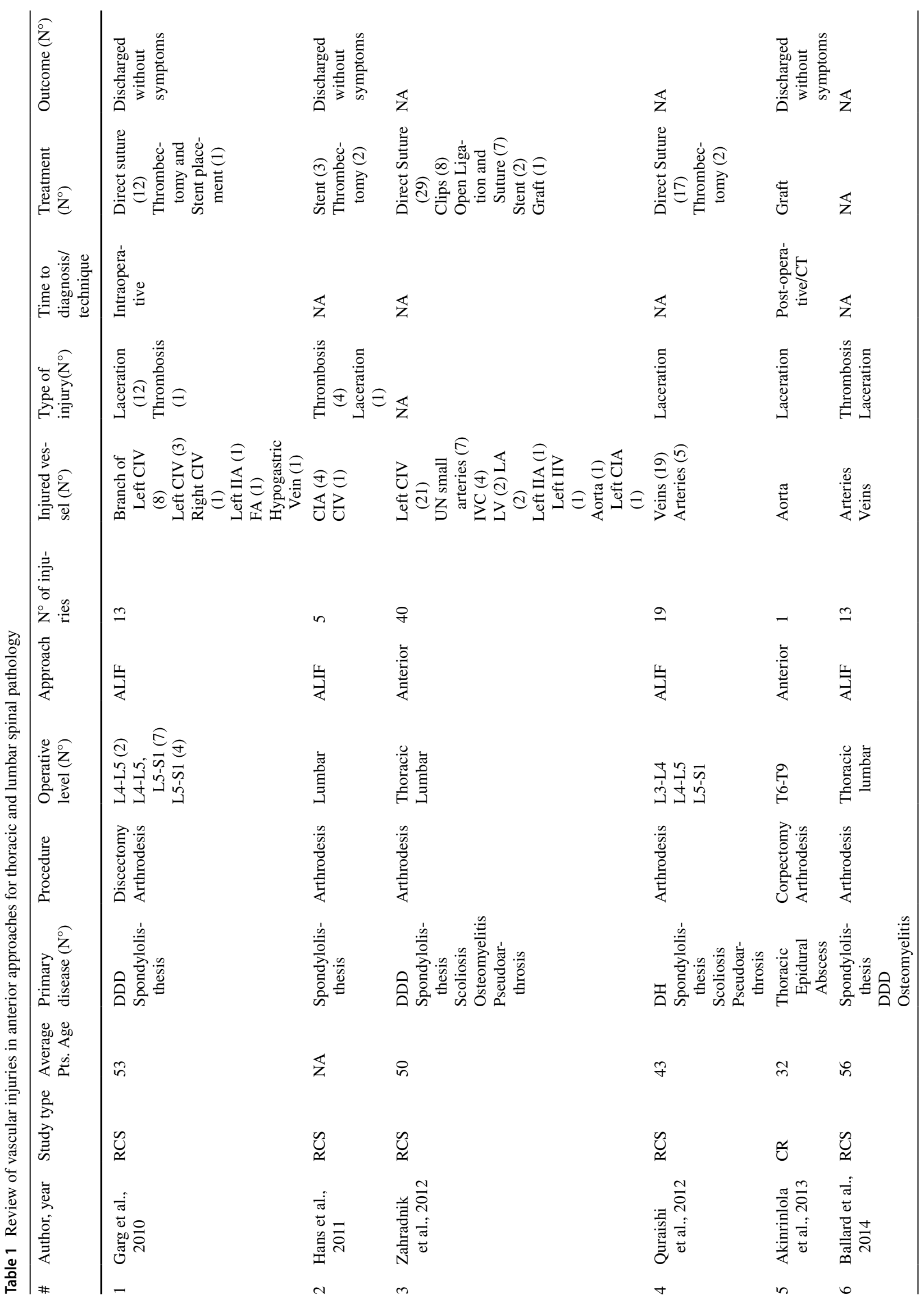




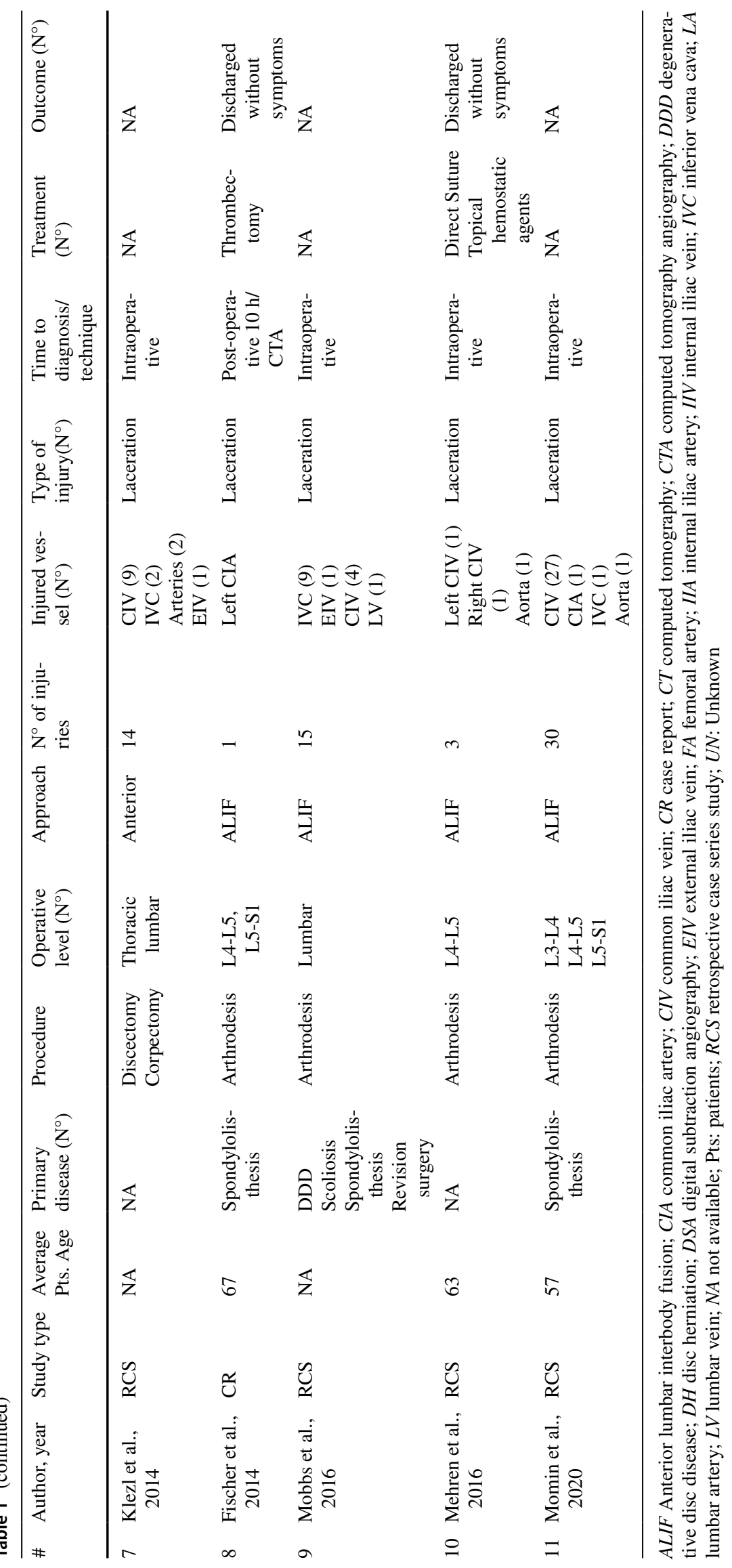









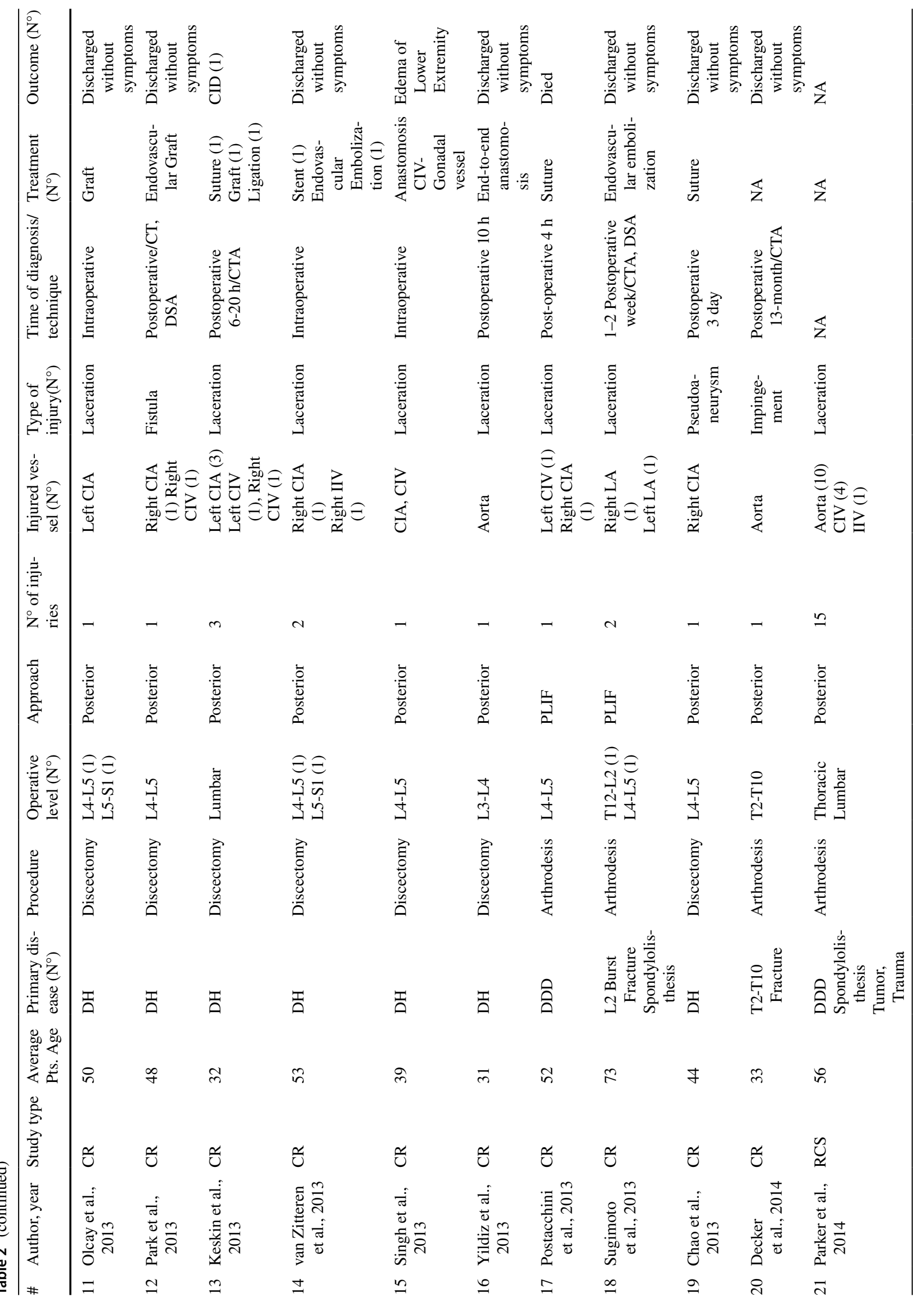




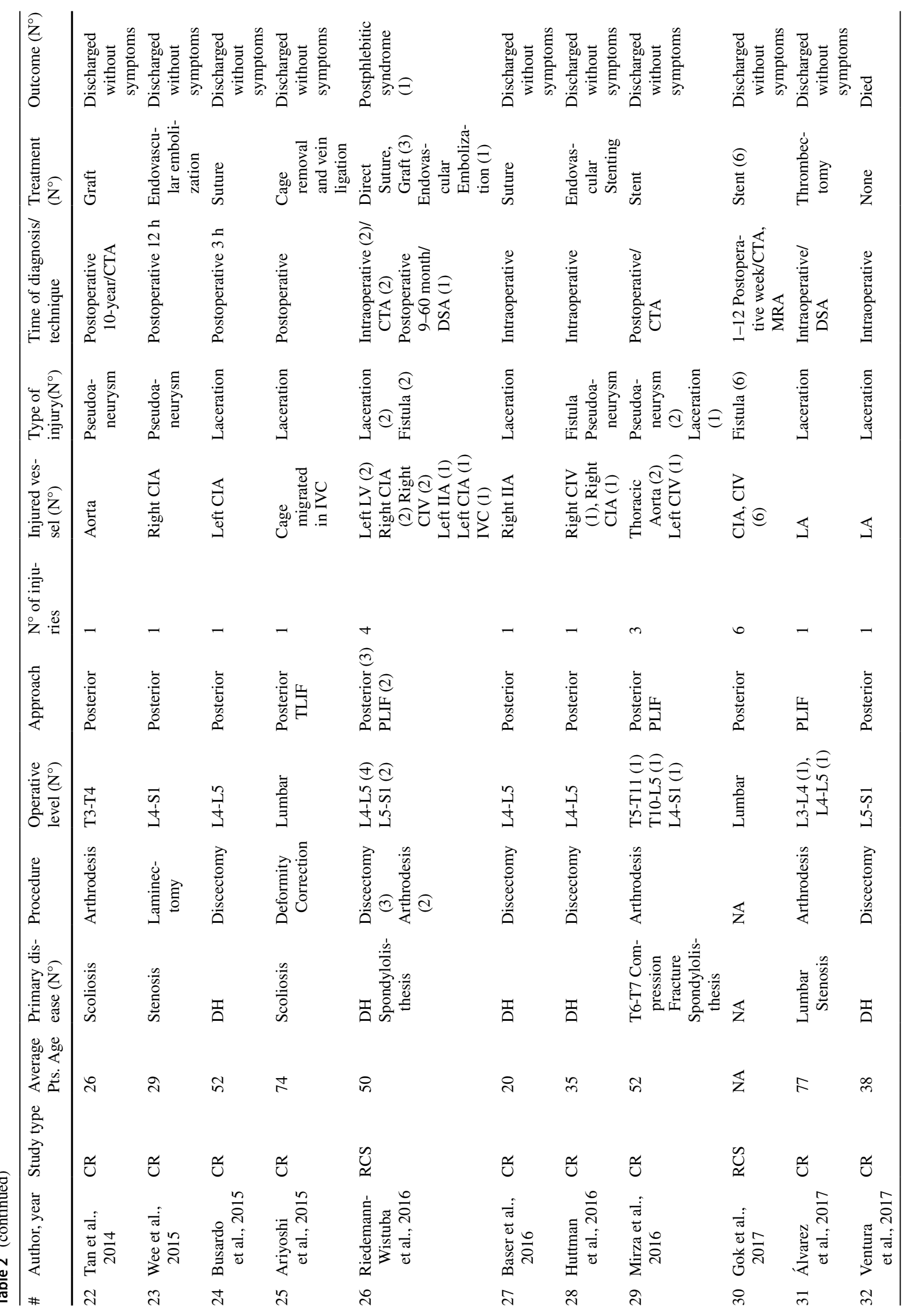




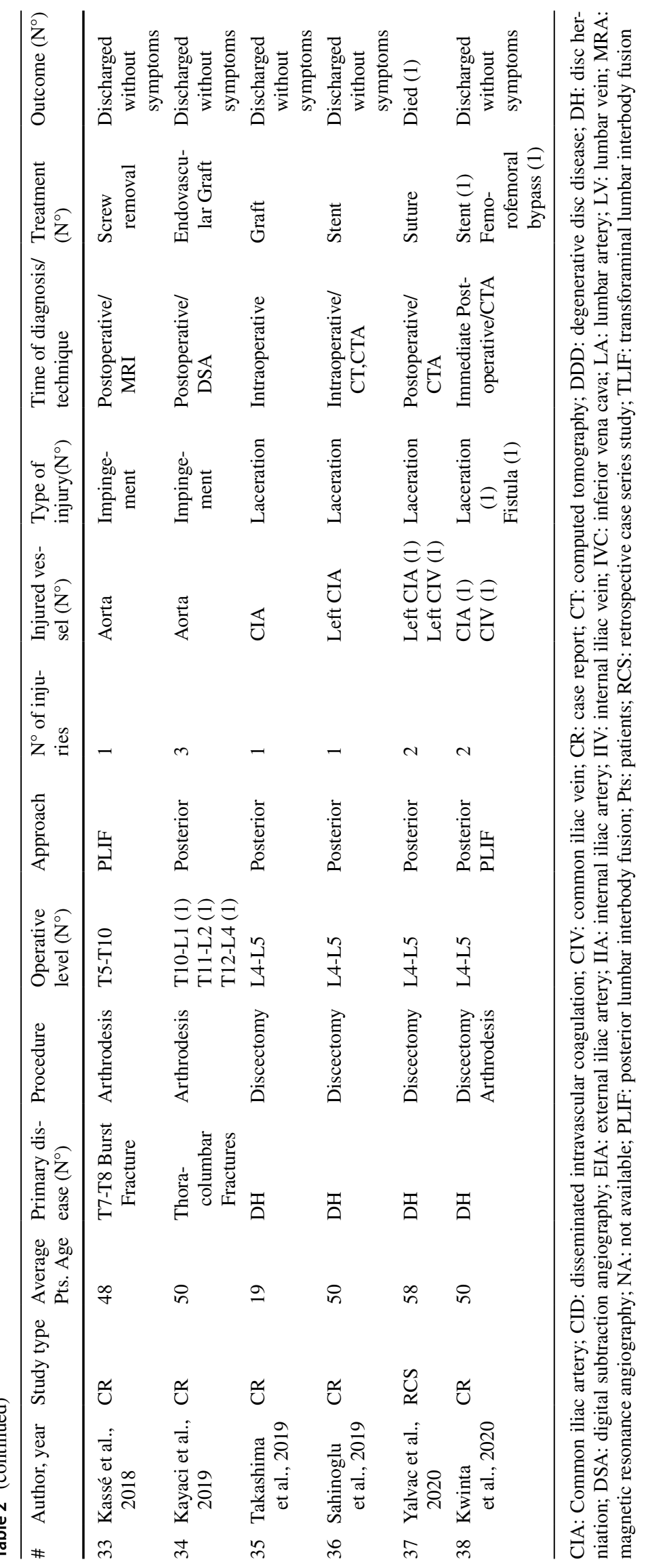




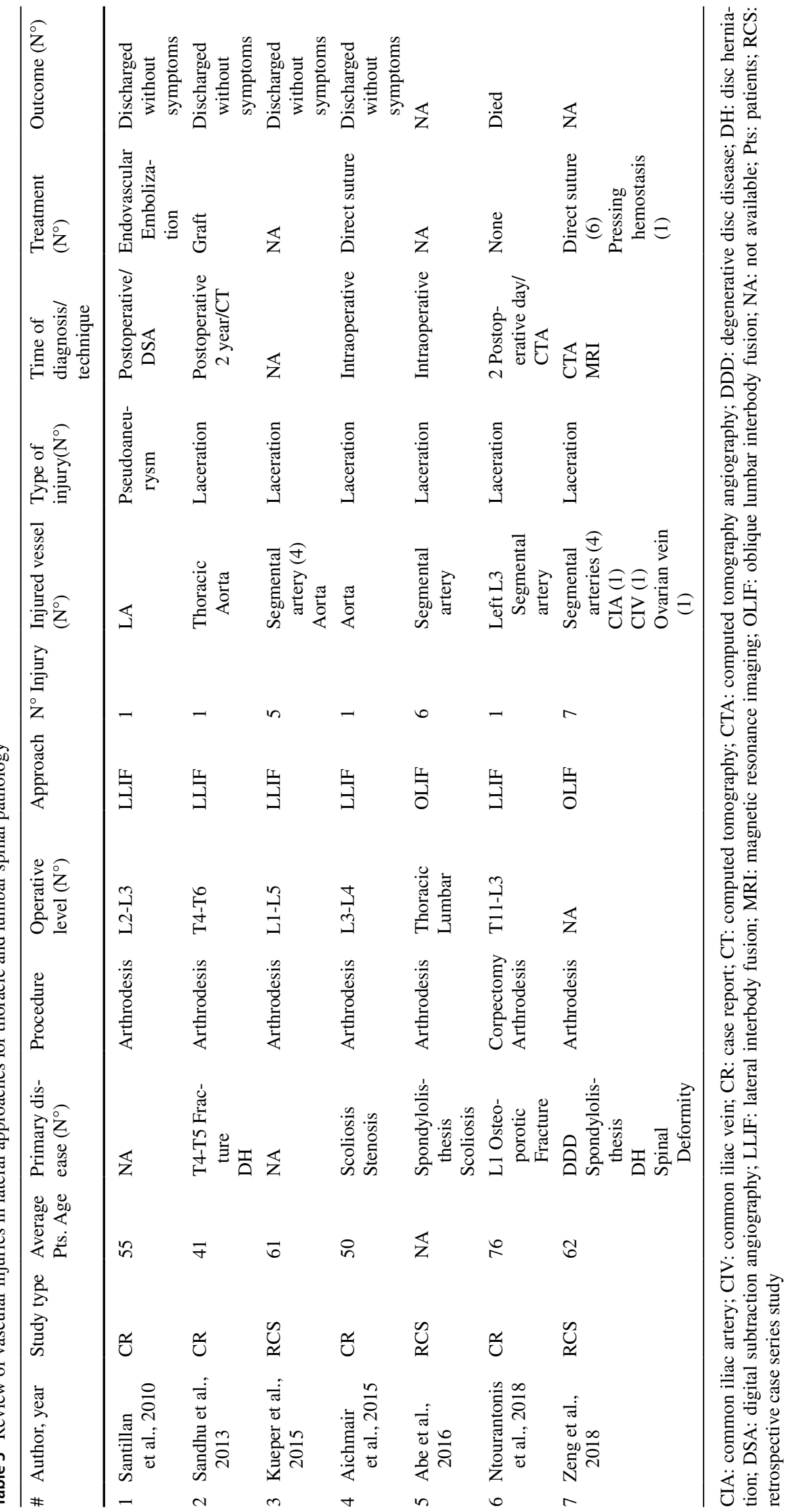


Indications for Anterior, Posterior and Lateral Thoracic and Lumbar Spinal Surgery

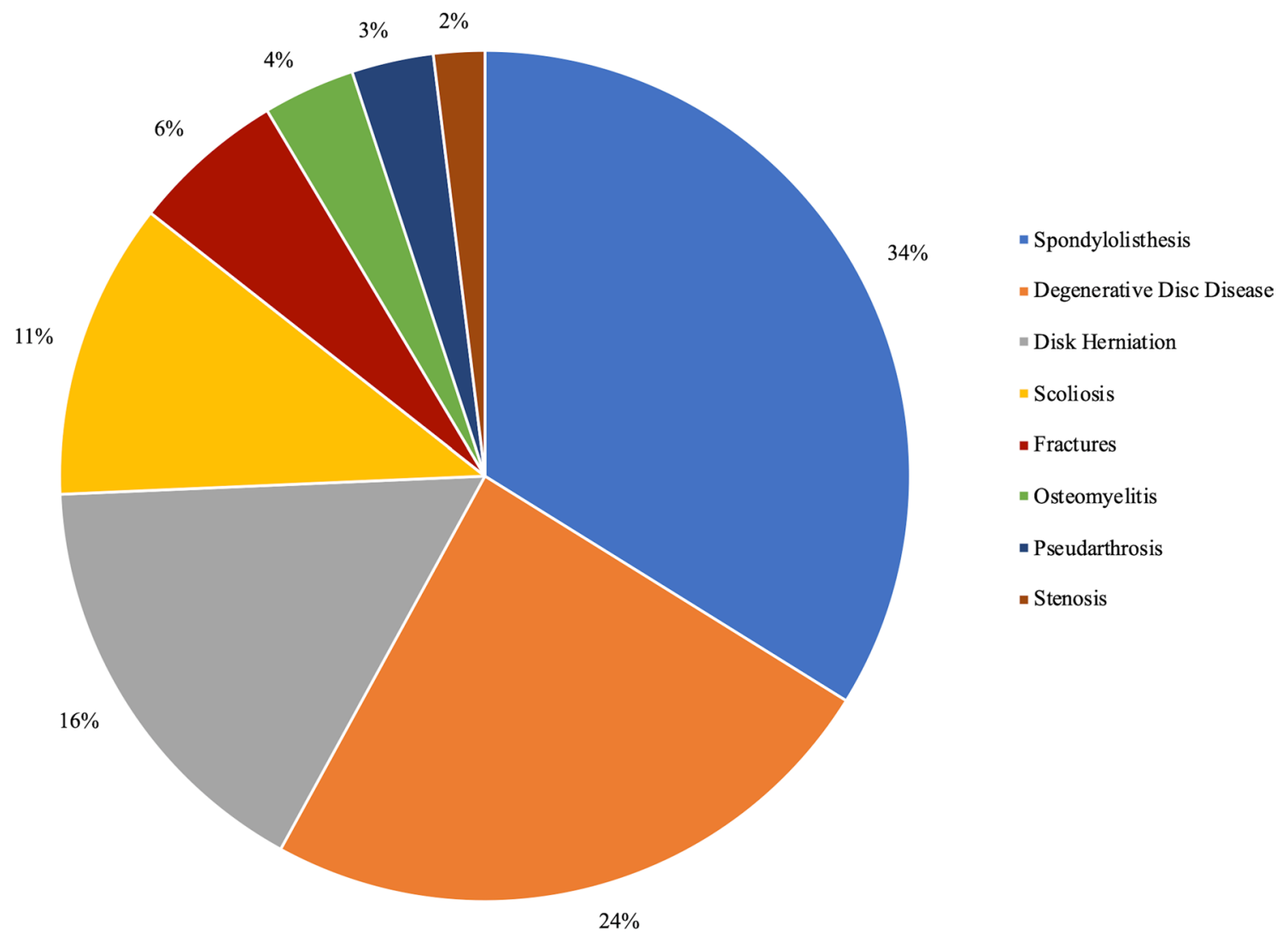

Fig. 2 Pie graph showing the main indications for anterior, posterior, and lateral thoracic and lumbar spinal surgery

lumbar interbody fusion (PLIF) in 20 cases. Among the lateral approaches, oblique lumbar interbody fusion (OLIF) and lateral lumbar interbody fusion (LLIF) were performed in 13 and 9 cases, respectively (Fig. 4).

\section{Injured vessels}

Two hundred and sixty-one vascular injuries were reported, with a prevalence of venous ones (56\%). The most involved vessels in the order of frequency were as follows: common iliac vein (CIV) (38\%), common iliac artery (CIA) (16\%), aorta (12\%), lumbar artery (LA) $(8 \%)$, inferior vena cava (IVC) $(7 \%)$, and segmental arteries (SA) (6\%). During anterior approaches, the most affected vessels were the CIV (49\%), IVC (10\%), CIA (4\%), and aorta (3\%). Conversely, CIA, CIV, aorta, and LA were involved in posterior approaches. The lateral approach was mainly associated with injury of the SA (54\%) (Fig. 5).

\section{Mechanism of injury}

The most frequent type of injury was by far a direct laceration of the vessel (81\%), whereas thrombosis (8\%), fistula (5\%), pseudoaneurysm (3\%), and impingement (3\%) had a lower incidence.

\section{Time to diagnosis}

A direct inspective intraoperative diagnosis was achieved in 102 cases (39\%). In the remaining 55 patients where the data were reported, computed tomography angiography (CTA), digital subtraction angiography (DSA), and computed tomography (CT) led to the diagnosis in $62 \%, 29 \%$, and $9 \%$ of cases, respectively, for both arterial and venous injuries.

\section{Repairing strategies}

Direct repair with sutures of the artery or vein was possible in 113 patients. Endovascular techniques allowed to 


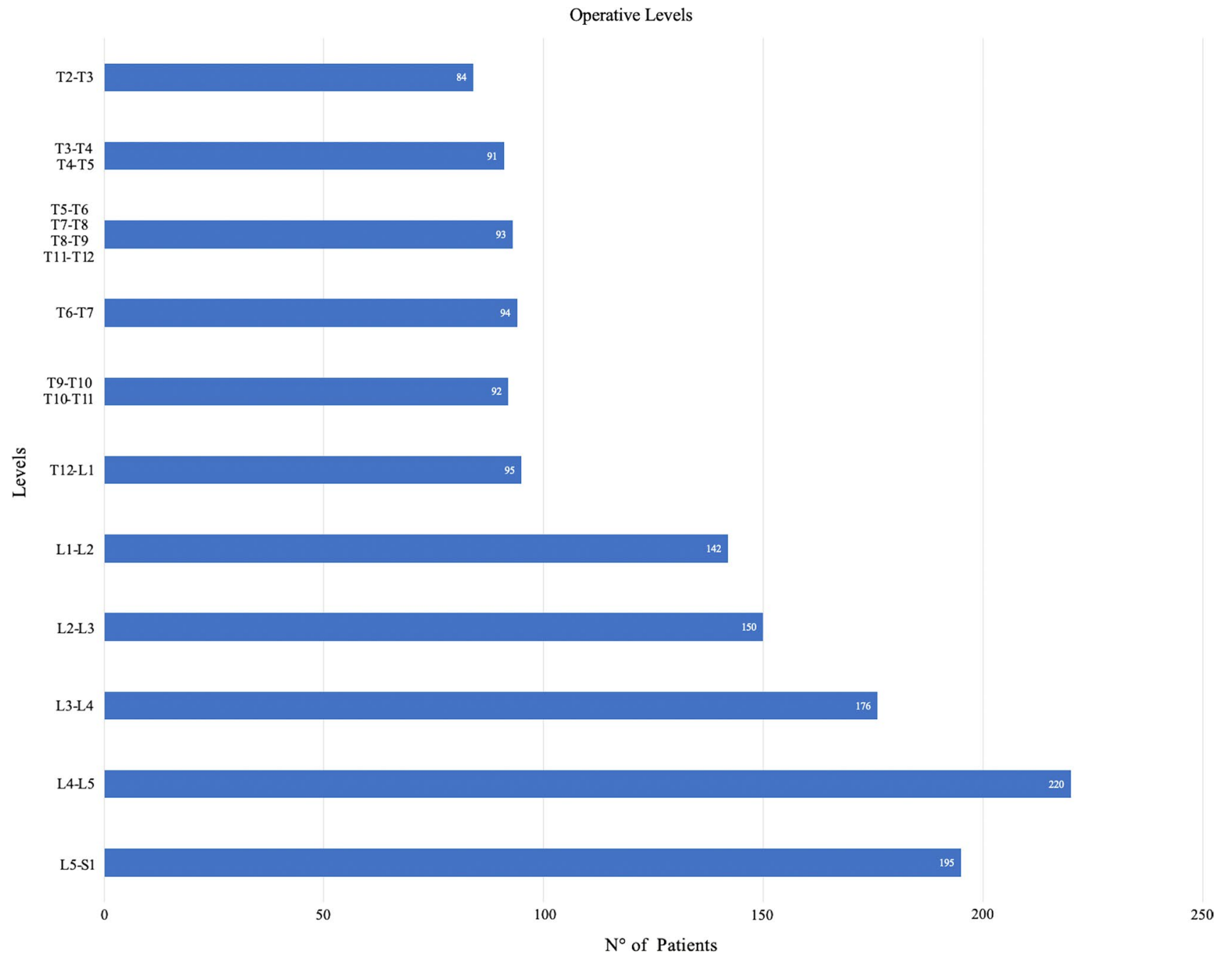

Fig. 3 Bar graph reporting the operative levels

treat the vascular damage in 56 cases; within these, stentgraft, thrombectomy, and embolization were utilized in $21 \%, 4 \%$, and $4 \%$ of cases, respectively. In surgical repairing techniques, clipping, anastomosis, and bypass were performed in $4 \%, 3 \%$, and $1 \%$ of patients, respectively. The release of topical hemostatic agents was sufficient in only 4 cases $(2 \%)$.

\section{Overall outcome, morbidity, and mortality rate}

Eighty-four patients (32\%) were discharged without symptoms. Only for posterior approaches, one case of paraplegia, one of disseminated intravascular coagulation, one of edema of the lower extremity, and one of postphlebitic syndrome were recorded, with a morbidity rate of $1 \%$. The overall mortality calculated on the pooled cohort was $2 \%$, of which the $90 \%$ (7 patients) for the posterior approach.

\section{Discussion}

The present literature review is aimed at an overview of the rate of iatrogenic approach-related vascular complications in thoracic and lumbar spine surgery. Questions about a putative correlation between the type of surgical corridor, and rate and type of injury have been addressed, in the obvious assumption that prompt recognition of these harmful complications is paramount for appropriate and effective management.

\section{Anterior approaches}

Anterior approaches to the thoracic and lumbar spine provide better exposure of the ventral surface of vertebral discs, with the main advantage of avoiding manipulation of the paravertebral muscles and ligaments, and a consequent lesser postoperative pain and risk of mechanical instability, 


\section{INCIDENCE OF VASCULAR INJURIES}

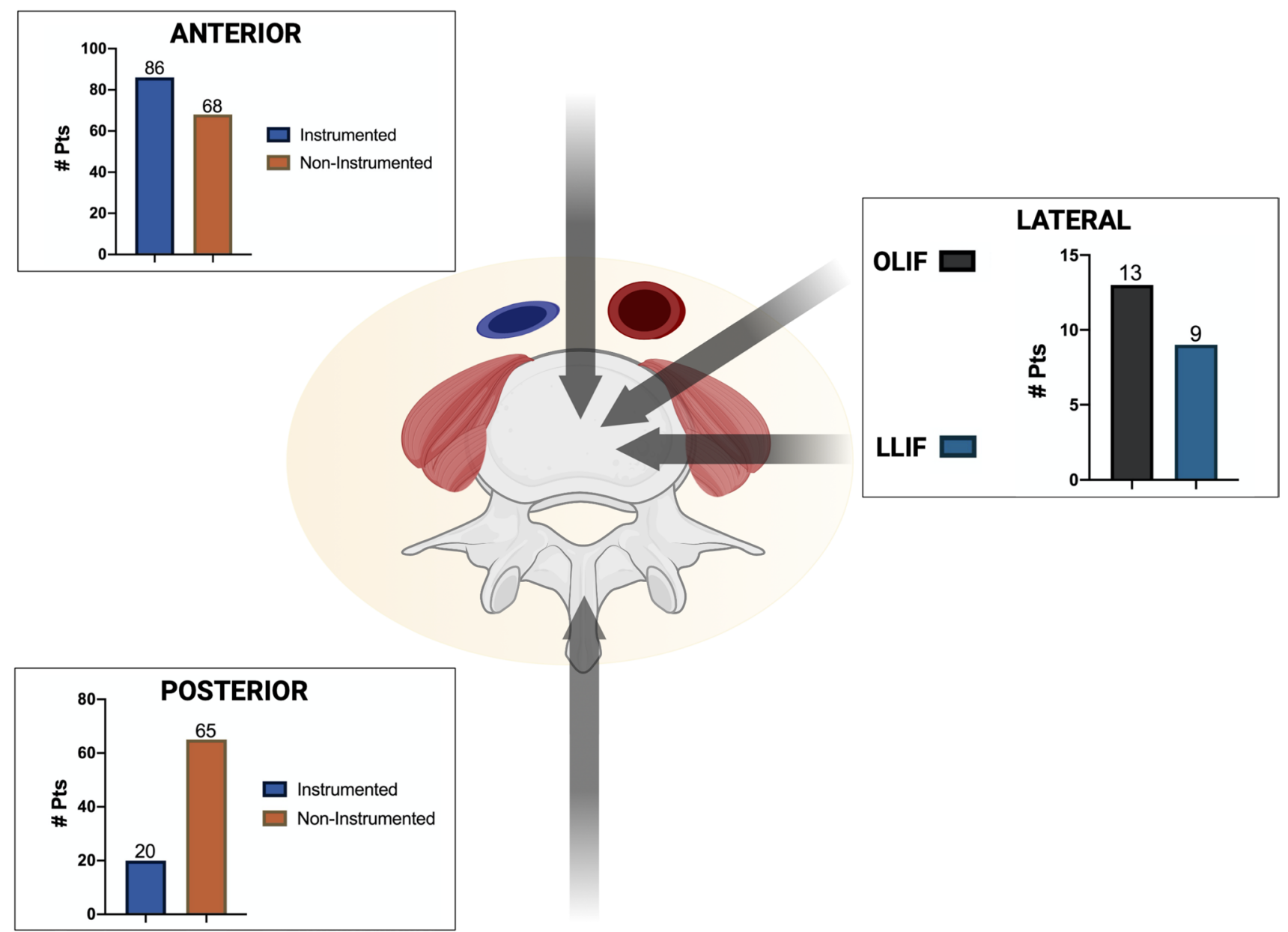

Fig. 4 Incidence of vascular injuries according to the type of approach

as well as direct access to the disc and release of the anterior longitudinal ligament (ALL), placement of cages with a wider footprint and possibility of achieving better restoration of lumbar lordosis [23]. During anterior approaches, the thoracoabdominal aorta, vena cava, iliac vein, and segmental vessels are mobilized and retracted to reach the anterior surface of the spine, for levels above L5-S1. Accordingly, the incidence of damages of the abdominal vessels unavoidably increased, resulting in a higher relative risk of vascular injuries related to the anterior approaches [4, 24].

Concerning the transthoracic anterior approaches, Ballard et al. reviewed 617 anterior thoracic and lumbar spine exposures, reporting 13 (2\%) vascular injuries [25]. Intercostal arteries and thoracic aorta were the most affected in their series.

Clip ligation of the intercostal arteries, lung deflation, mobilization of the diaphragm, and removal of the inferior ribs were the strategies suggested facilitating disc exposure and at the same time reducing the risk of thoracic vessels' lesions [25].

About the lumbar and lumbosacral spine, Garg et al. estimated the incidence of vascular injuries in 212 patients that underwent ALIF [26], of which $6.1 \%$ of cases were intraoperative vascular damages and a direct laceration of left CIV in $61.5 \%$ of cases. Notably, L5-S1 was the level affected in $70 \%$ of these procedures, where usually there is minimal mobilization of the vasculature, given that the procedure is carried out below the bifurcation and in between the iliac vessels.

In 2012, Zahradnik et al. published a retrospective review on 269 thoracic and lumbar anterior surgical procedures where they found a rate of vascular injuries of $13.8 \%$, along with the involvement of the CIV in $52.5 \%$ of cases [6]. On a further series of 1262 left-sided anterior thoracic and lumbar surgeries by Klezl and colleagues, the overall rate of vascular injuries was $1.1 \%$, with the CIV interested in $65 \%$ 
INCIDENCE OF VASCULAR INJURIES

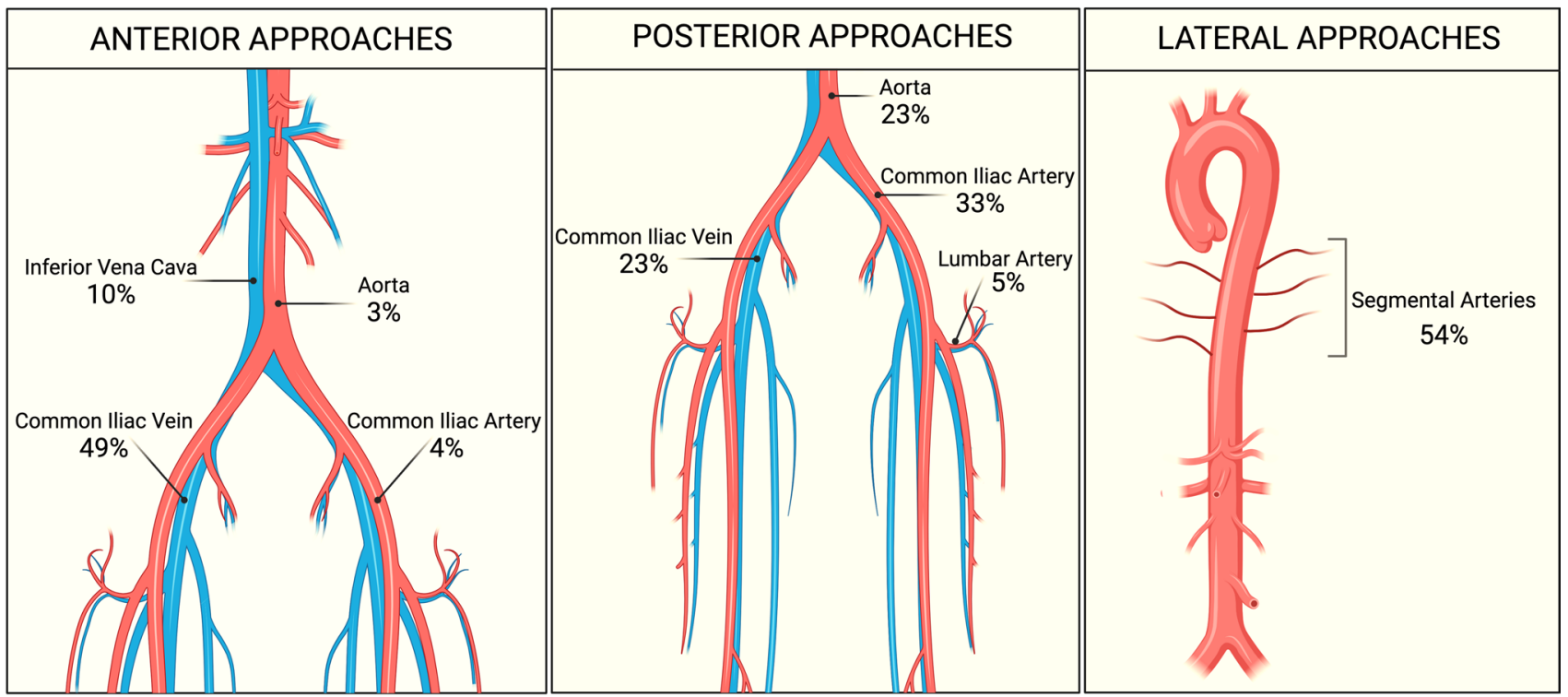

Fig. 5 Incidence of vascular injuries in anterior, posterior, and lateral approaches

of patients [27]. Recently, in 2020, Momin et al. reported 30 vascular lesions during 660 ALIFs, 27 of which were once again intraoperative lacerations of the CIV [28].

By the literature, our review highlighted a higher incidence of vascular lesions during anterior approaches (59\%) in comparison with the posterior (33\%) and lateral ones $(8 \%)$. Not surprisingly, this rate was even higher for instrumented procedures because the positioning of pointed pedicle screws could easily injure vascular structures. At L5-S1, CIV was the most affected vessel (49\%). Conversely, IVC and iliolumbar veins were mostly injured during procedures targeting the L4-L5 and L3-L4 disc space, respectively. The most frequent mechanism of damage during anterior approaches is the direct avulsion of a vein encountered along the surgical route. The rationale explanation lies in the greater fragility of the venous wall, consisting of a minor elastic component, making them more vulnerable than the arteries. On the other hand, despite an increased risk of vascular injury, anterior access allows for an easier exposure of the damaged vessel, direct control of the bleeding, and repairing of the vessel wall, which is achieved by means of a direct, often straightforward, suture in most cases. Vein repairing strategy usually entails the employment of monofilament nonabsorbable stiches.

Concerning the arterial counterpart, the CIA was found to be the most damaged during anterior procedures. CIA avulsion is a fearsome complication of the anterior lumbar retroperitoneal approach that can lead to claudication, ischemia, and lifetime paraplegia. In 2011, Hans et al. reported 4 cases of CIA injuries, consisting of thrombosis in 3 cases and laceration in one case $[29,30]$. Retraction and mobilization of the great arteries are thought to potentially cause a small dissection of the intimal wall, ultimately resulting in thrombosis and vessel occlusion. In anterior lumbar procedures, bilateral pulse oximetry has been suggested as a useful tool to detect intraoperatively the arterial vessel damage at an early stage, allowing its immediate treatment [31]. Arterial repairing techniques generally encompass an open arteriotomy, angioplasty, or endovascular stent placement [32-35].

\section{Posterior approaches}

Posterior approaches are related to a significantly lower risk of vascular complications, negligible in the present review $(0.05 \%-0.08 \%)$. The rationale lies in the anatomy of the surgical route, which does not require exposure and mobilization of the retroperitoneal vessels [36, 37].

Some case reports have discussed injuries to the thoracic aorta during posterior instrumented surgery, almost all sustained by impingement or avulsion of the artery leading to a delayed hemothorax [38-40]. Parker et al. retrospectively examined 964 patients who underwent thoracic and lumbar screw fixation procedures, finding 10 thoracic pedicle screws that encroached the thoracic aorta. Four lumbar screws damaged the CIV and 1 the IIV [20]. Riedemann-Wistuba et al. reported 4 cases of vascular injuries that occurred during PLIF, involving the CIA and CIV [41]. Kwinta et al. recently reported 2 further cases of iliac vessel injuries during PLIF. The first was a direct avulsion of the CIA, which was treated by means of stent 
placement, whereas the second consisted of a laceration of iliac vessels, leading to the formation of an arteriovenous fistula. The latter was repaired by a temporary femorofemoral bypass, followed by stent implantation in the right CIA [42]. Concerning the non-instrumented lumbar procedures, the risk of vascular injuries during lumbar disc surgery is low but should not be underestimated as this is a potentially catastrophic complication, to the point to be defined by some authors as the nightmare of this procedure [3, 43-51].

On a small series, Bozok et al. documented 6 CIA injuries (5 left, 1 right) and 2 CIV (1 left, 1 right) occurred in 7 lumbar discectomies [52].

Our study demonstrated that $33 \%$ of vascular injuries occurred during posterior approaches, of which only $24 \%$ happened during instrumented surgery.

In posterior instrumented surgery, the vascular injuries are theoretically attributable to the incorrect placement of the screw tip in the proximity to the vessel wall. Conversely, a possible explanation for the paradoxically even higher rate of vascular injuries in posterior non-instrumented surgery lies in the different aim of most of the posterior non-instrumented approaches where, for example in lumbar diskectomy, it is required to manipulate the disc with a consequent higher probability that curettes or rongeurs may accidentally be deepened beyond the anterior longitudinal ligament injuring the retroperitoneal vessels. This aspect makes complex also repairs of these injuries that are burdened by significant mortality as reported, for example, in lumbar diskectomy [36, 49, 53].

CIA, CIV, and aorta were involved in $40 \%, 28 \%$, and $28 \%$ of cases, respectively. Laceration of CIA causes a wide retroperitoneal hemorrhage, which is not always identifiable intraoperatively, and that has to be always suspected in the light of a sudden intraoperative or postoperative hypotension.

Contrary to the anterior approaches, the main difficulties in vascular repairing of a retroperitoneal major vessel during the posterior routes lie in the urgent need for turning the patient supine to perform an anterior, retro- or transperitoneal approach.

Secondary injuries, caused by the impingement of hardware or cages to the vessel wall, are generally managed by a redo surgery or implant removal.

The formation of pseudoaneurysms and arteriovenous fistulas has also been described as delayed consequences of a chronic mechanical insult to the vessel wall. The presence of a pseudoaneurysm should be suspected in the presence of a pulsating abdominal mass with distension and pain, whereas arteriovenous fistulas may cause cardiopulmonary disturbances, tachycardia, intermittent claudication, and lower limbs edema [36, 44, 52, 54].
Endovascular techniques, such as stent-graft placement, embolization, and thrombectomy, have proven to be useful in the re-establishment of blood flow $[55,56]$.

\section{Lateral approaches}

In 2006, Ozgur et al. firstly described the lateral approach to the lumbar spine, namely the LLIF or XLIF [57]. It provides access to the lumbar vertebral discs through a retroperitoneal transpsoas route. Later, the so-called anterior to psoas approach, also known as OLIF, was introduced to avoid the mechanical consequences of the psoas muscles imbalance $[58,59]$.

Sandhu et al., in 2013, reported 2 cases of screw penetration of the thoracic aorta during lateral transthoracic approaches, both treated by open repair [60]. In 2015, Kueper et al. estimated at $0.056 \%$ the incidence of vascular injuries in 900 patients who underwent LLIF [61]. In their series, 4 patients incurred segmental vessel damage and 1 sustained a direct laceration of the abdominal aorta. All injuries were repaired by direct ligature or suture, and no patients suffered long-term sequelae [61].

In 2016, Abe et al. conducted a retrospective review of 155 patients who underwent an OLIF procedure, where 6 segmental vessel injuries (3\% of the overall series) were reported [62].

Zeng et al., in 2018, analyzed 235 OLIFs, reporting 7 cases of vascular damages of segmental arteries in 4 cases, iliac vessels in 2 cases, and ovarian vein in the remaining case [63].

The present review overall found 22 vascular injuries (8\%) during lateral approaches. The most frequent mechanism of damage was the direct focal laceration of the segmental vessels (54\% of cases), because of the need for mobilization and ligation during LLIF and OLIF. Segmental vessel avulsion can be promptly controlled by direct pressure and topical hemostatic agents.

\section{Management tips}

Regardless of the surgical corridor, some important aspects emerged from this study, which should be intended as tips to decrease the risk of iatrogenic vascular injuries during spine surgery, as well as to adequately manage them during or after surgery.

The vascular anatomy should be understood preoperatively to identify potential variants, especially when planning anterior or lateral thoracic and lumbar spine approaches.

Preoperative planning is crucial also for cervical spine surgery, where the detection of the carotid and vertebral artery courses and eventual anatomical variants is fundamental. 
Iatrogenic carotid artery injuries during anterior cervical spine surgeries are rare and not extensively reported in the literature. There is neither evidence that the prolonged carotid artery sheath traction during anterior cervical approaches results in the reduction of carotid blood flow and cerebrovascular accidents [64-66]. Vertebral artery damages due to anterior cervical spine procedures are infrequent, with an incidence of $0.1-0.5 \%[55,67,68]$.

As regards posterior cervical approaches, especially for upper cervical spine surgeries, the course of both vertebral arteries must be investigated preoperatively. Its laceration is a potentially fatal complication with an incidence rate ranging between 0.07 and $8 \%$ [69, 70].

Diagnostic tools to be considered are CT or MRI angiography, and in selected cases, additional vascular studies can be performed as needed [71-73].

In addition, the depth of the vertebral disc to the retroperitoneum should be measured on axial imaging studies for a safer placement of the surgical instruments $[46,54,74]$.

Surgical timeout must include the presence of blood products and immediate needs tools such as large bore suckers, topical hemostats, clips, ligature, and vascular sutures [30, 75].

Adequate intraoperative hemodynamic parameters monitoring must be ensured by the anesthesiology team, with immediate detection of changes in pressure, hematocrit, and arterial pulse $[4,37]$.

After surgery, in case of suspected vascular injury, it is mandatory to perform CTA or, if the patient is hemodynamically stable, and angiography. Furthermore, dye-based methods of intraoperative visualization of the blood flow are useful to early detect the source of bleeding and also to perform a timely treatment by means of techniques coming from neurovascular surgery and described elsewhere by our group [76, 77].

\section{Limitations}

This literature review has some limitations. They are the heterogeneity as well as retrospective nature of the studies included of which more than half results from case reports (68\%) and involved a relatively limited number of patients. These aspects inevitably rise the likelihood of biases. A further limit to be taken into account lies in the overall experience of the surgical teams, which affects both the rate of vascular injury and the promptness and efficacy of the repairing techniques.

\section{Conclusion}

The literature reported an overall incidence of iatrogenic vascular injuries during thoracic and lumbar spine surgery which is not negligible. The mortality rate of these complications varies widely among the series included in the review, ranging between 15 and $65 \%$, also considering the prevalence of case reports $(68 \%)$ and the low level of evidence.

Anterior approaches to the thoracic and lumbar spine are burdened by a higher risk of direct venous avulsion, especially CIV and IVC. Posterior instrumented fusion has been associated with a greater risk of damage to iliac vessels and aorta. The more recent lateral corridors have to face the handling of the segmental vessels. Repairing strategies involve direct suture and endovascular techniques, both having a primary role in decreasing the overall mortality of these rare but severe complications.

Funding Open access funding provided by Università degli Studi di Pavia within the CRUI-CARE Agreement.

\section{Declarations}

Conflict of interest The authors declare that there is no conflict of interest.

Open Access This article is licensed under a Creative Commons Attribution 4.0 International License, which permits use, sharing, adaptation, distribution and reproduction in any medium or format, as long as you give appropriate credit to the original author(s) and the source, provide a link to the Creative Commons licence, and indicate if changes were made. The images or other third party material in this article are included in the article's Creative Commons licence, unless indicated otherwise in a credit line to the material. If material is not included in the article's Creative Commons licence and your intended use is not permitted by statutory regulation or exceeds the permitted use, you will need to obtain permission directly from the copyright holder. To view a copy of this licence, visit http://creativecommons.org/licenses/by/4.0/.

\section{References}

1. Anda S, Aakhus S, Skaanes KO, Sande E, Schrader H (1991) Anterior perforations in lumbar discectomies. A report of four cases of vascular complications and a CT study of the prevertebral lumbar anatomy. Spine (Phila Pa 1976) 16:54-60

2. Ramirez LF, Thisted R (1989) Complications and demographic characteristics of patients undergoing lumbar discectomy in community hospitals. Neurosurgery 25: 226-230; discussion 230-221. doi: https://doi.org/10.1097/00006123-198908000-00012

3. Bingol H, Cingoz F, Yilmaz AT, Yasar M, Tatar H (2004) Vascular complications related to lumbar disc surgery. J Neurosurg 100:249-253. https://doi.org/10.3171/spi.2004.100.3.0249

4. Inamasu J, Guiot BH (2006) Vascular injury and complication in neurosurgical spine surgery. Acta Neurochir (Wien) 148:375-387. https://doi.org/10.1007/s00701-005-0669-1

5. Seeley SF, Hughes CW, Jahnke EJ Jr (1954) Major vessel damage in lumbar disc operation. Surgery 35:421-429

6. Zahradnik V, Lubelski D, Abdullah KG, Kelso R, Mroz T, Kashyap VS (2013) Vascular injuries during anterior exposure of the thoracolumbar spine. Ann Vasc Surg 27:306-313. https://doi. org/10.1016/j.avsg.2012.04.023 
7. Kim HS, Chong HS, Nanda A, Park JO, Moon SH, Lee HM, Kim HJ, Park CK, Park YS, Lee SH, Moon ES (2010) Vascular injury in thoracolumbar spinal surgeries and role of angiography in early diagnosis and management. J Spinal Disord Tech 23:418-424. https://doi.org/10.1097/BSD.0b013e3181b63f33

8. Vraney RT, Phillips FM, Wetzel FT, Brustein M (1999) Peridiscal vascular anatomy of the lower lumbar spine. An endoscopic perspective. Spine (Phila Pa 1976) 24: 2183-2187. doi: https://doi. org/10.1097/00007632-199911010-00002

9. Ezra E, Richenberg JL, Smellie WA (1996) Major vascular injury during lumbar laminectomy. J R Soc Med 89:108p-109p

10. Goodkin R, Laska LL (1998) Vascular and visceral injuries associated with lumbar disc surgery: medicolegal implications. Surg Neurol 49: 358-370; discussion 370-352. doi: https://doi.org/10. 1016/s0090-3019(97)00372-8

11. Birkeland IW, Taylor TK (1969) Major vascular injuries in lumbar disc surgery. J Bone Joint Surg Br 51:4-19

12. Sande E, Myhre HO, Witsøe E, Lundbom J, Stolt-Nielsen A, Anda S (1991) Vascular complications of lumbar disc surgery. Case report Eur J Surg 157:141-143

13. Jarstfer BS, Rich NM (1976) The challenge of arteriovenous fistula formation following disk surgery: a collective review. J Trauma 16:726-733. https://doi.org/10.1097/00005373-19760 9000-00008

14. May AR, Brewster DC, Darling RC, Browse NL (1981) Arteriovenous fistula following lumbar disc surgery. Br J Surg 68:41-43. https://doi.org/10.1002/bjs.1800680113

15. Boyd DP, Farha GJ (1965) Arteriovenous fistula and isolated vascular injuries secondary to intervertebral disk surgery: report of four cases and review of the literature. Ann Surg 161:524-531. https://doi.org/10.1097/00000658-196504000-00006

16. Brewster DC, May AR, Darling RC, Abbott WM, Moncure AC (1979) Variable manifestations of vascular injury during lumbar disk surgery. Arch Surg 114:1026-1030. https://doi.org/10.1001/ archsurg.1979.01370330048008

17. Schermann H, Mirovsky Y, Chechik Y (2019) Delayed penetration of the thoracic aorta by pedicle screws: a case report of screws left as-is. Spine (Phila Pa 1976) 44: E1169-e1171. doi: https://doi.org/ 10.1097/brs.0000000000003094

18. Mirza AK, Alvi MA, Naylor RM, Kerezoudis P, Krauss WE, Clarke MJ, Shepherd DL, Nassr A, DeMartino RR, Bydon M (2017) Management of major vascular injury during pedicle screw instrumentation of thoracolumbar spine. Clin Neurol Neurosurg 163:53-59. https://doi.org/10.1016/j.clineuro.2017.10.011

19. Tschoeke SK, Gahr P, Krug L, Kasper AS, Heyde CE, Ertel W (2011) Late diagnosis of pedicle screw malplacement with perforation of the thoracic aorta after posterior stabilization in a patient with multiple myeloma: case report. (Spine Phila Pa 1976). https://doi.org/10.1097/BRS.0b013e318202e4d1

20. Parker SL, Amin AG, Santiago-Dieppa D, Liauw JA, Bydon A, Sciubba DM, Wolinsky JP, Gokaslan ZL, Witham TF (2014) Incidence and clinical significance of vascular encroachment resulting from freehand placement of pedicle screws in the thoracic and lumbar spine: analysis of 6816 consecutive screws. Spine (Phila Pa 1976) 39:683-687. https://doi.org/10.1097/BRS.0000000000 000221

21. Sevuk U, Mesut A, Kiraz I, Kose K, Ayaz F, Erkul A (2016) Delayed presentation of aortic injury by a thoracic pedicle screw. J Card Surg 31:220-230. https://doi.org/10.1111/jocs.12718

22. Weiss BD (2004) SORT: Strength of recommendation taxonomy. Fam Med 36:141-143

23. Phan K, Fadhil M, Chang N, Giang G, Gragnaniello C, Mobbs RJ (2018) Effect of smoking status on successful arthrodesis, clinical outcome, and complications after anterior lumbar interbody fusion (ALIF). World Neurosurg 110:e998-e1003. https://doi.org/ 10.1016/j.wneu.2017.11.157

24. Chiriano J, Abou-Zamzam AM Jr, Urayeneza O, Zhang WW, Cheng W (2009) The role of the vascular surgeon in anterior retroperitoneal spine exposure: preservation of open surgical training. J Vasc Surg 50:148-151. https://doi.org/10.1016/j.jvs.2009. 01.007

25. Ballard JL, Carlson G, Chen J, White J (2014) Anterior thoracolumbar spine exposure: critical review and analysis. Ann Vasc Surg 28:465-469. https://doi.org/10.1016/j.avsg.2013.06.026

26. Garg J, Woo K, Hirsch J, Bruffey JD, Dilley RB (2010) Vascular complications of exposure for anterior lumbar interbody fusion. J Vasc Surg 51:946-950; discussion 950. doi: https://doi.org/10. 1016/j.jvs.2009.11.039

27. Klezl Z, Swamy GN, Vyskocil T, Kryl J, Stulik J (2014) Incidence of vascular complications arising from anterior spinal surgery in the thoraco-lumbar spine. Asian Spine J 8:59-63. https://doi.org/ 10.4184/asj.2014.8.1.59

28. Momin AA, Barksdale EM 3rd, Lone Z, Enders JJ, Nowacki AS, Winkelman RD, Krantz M, Hardy DM, Steinmetz MP (2020) Exploring perioperative complications of anterior lumber interbody fusion in patients with a history of prior abdominal surgery: A retrospective cohort study. Spine J. https://doi.org/10.1016/j. spinee.2020.03.009

29. Hans SS, Shepard AD, Reddy P, Rama K, Romano W (2011) Iatrogenic arterial injuries of spine and orthopedic operations. J Vasc Surg 53:407-413. https://doi.org/10.1016/j.jvs.2010.08.084

30. Vaccaro AR, Albert TJ (2011) Spine Surgery: Tricks of the Trade. Thieme

31. Konig MA, Leung Y, Jurgens S, MacSweeney S, Boszczyk BM (2011) The routine intra-operative use of pulse oximetry for monitoring can prevent severe thromboembolic complications in anterior surgery. Eur Spine J 20:2097-2102. https://doi.org/10.1007/ s00586-011-1900-9

32. Loh SA, Maldonado TS, Rockman CB, Lamparello PJ, Adelman MA, Kalhorn SP, Frempong-Boadu A, Veith FJ, Cayne NS (2012) Endovascular solutions to arterial injury due to posterior spine surgery. J Vasc Surg 55:1477-1481. https://doi.org/10.1016/j.jvs. 2010.10.064

33. Jim J, Sanchez LA, Geraghty PJ (2011) Endovascular repair of an intraoperative thoracic aortic injury during all-posterior vertebral column resection surgery. Ann Vasc Surg 25(132):e131-136. https://doi.org/10.1016/j.avsg.2010.04.002

34. Zerati AE, Leiderman DB, Teixeira WG, Narazaki DK, Cristante AF, Wolosker N, de Luccia N, Barros Filho TE (2017) Endovascular treatment of late aortic erosive lesion by pedicle screw without screw removal: case report and literature review. Ann Vasc Surg. https://doi.org/10.1016/j.avsg.2016.06.020

35. Claiborne P, Mallios A, Taubman K, Blebea J (2015) Endovascular repair of thoracic aortic injury after spinal instrumentation. $\mathrm{J}$ Vasc Surg Cases 1:264-267. https://doi.org/10.1016/j.jvsc.2015. 09.001

36. Papadoulas S, Konstantinou D, Kourea HP, Kritikos N, Haftouras N, Tsolakis JA (2002) Vascular injury complicating lumbar disc surgery. a systematic review. Eur J Vasc Endovasc Surg 24:189_ 195. https://doi.org/10.1053/ejvs.2002.1682

37. Denli Yalvac ES, Balak N (2020) The probability of iatrogenic major vascular injury in lumbar discectomy. Br J Neurosurg 34:290-298. https://doi.org/10.1080/02688697.2020.1736261

38. Clarke MJ, Guzzo J, Wolinsky JP, Gokaslan Z, Black JH 3rd (2011) Combined endovascular and neurosurgical approach to the removal of an intraaortic pedicle screw. J Neurosurg Spine 15:550-554. https://doi.org/10.3171/2011.7.SPINE10267

39. Decker S, Omar M, Krettek C, Muller CW (2014) Elective thoracotomy for pedicle screw removal to prevent severe aortic 
bleeding. World J Clin Cases 2:100-103. https://doi.org/10.12998/ wjcc.v2.i4.100

40. Watanabe K, Yamazaki A, Hirano T, Izumi T, Sano A, Morita O, Kikuchi R, Ito T (2010) Descending aortic injury by a thoracic pedicle screw during posterior reconstructive surgery: a case report. Spine (Phila Pa 1976) 35:E1064-1068. https://doi.org/10. 1097/BRS.0b013e3181ed29c1

41. Riedemann-Wistuba M, Alonso-Perez M, Llaneza-Coto JM (2016) Vascular complications associated with lumbar spinal surgery. Rev Esp Cir Ortop Traumatol 60:148-152. https://doi.org/10. 1016/j.recot.2014.09.006

42. Kwinta BM, Myszka AM, Bigaj MM, Dragan MR, Kenig J, Krzyzewski RM (2020) Iatrogenic common iliac vessel injury during routine degenerative lumbar spine surgery: report of 2 cases and review of literature. World Neurosurg 137:111-118. https://doi.org/10.1016/j.wneu.2020.01.168

43. Busardò FP, Frati P, Carbone I, Pugnetti P, Fineschi V (2015) Iatrogenic left common iliac artery and vein perforation during lumbar discectomy: a fatal case. Forensic Sci Int 246:e7-11. https:// doi.org/10.1016/j.forsciint.2014.11.006

44. Döşoğlu M, Iş M, Pehlivan M, Yildiz KH (2006) Nightmare of lumbar disc surgery: iliac artery injury. Clin Neurol Neurosurg 108:174-177. https://doi.org/10.1016/j.clineuro.2004.11.019

45. Fruhwirth J, Koch G, Amann W, Hauser H, Flaschka G (1996) Vascular complications of lumbar disc surgery. Acta Neurochir (Wien) 138:912-916. https://doi.org/10.1007/bf01411278

46. Erkut B, Unlü Y, Kaygin MA, Colak A, Erdem AF (2007) Iatrogenic vascular injury during to lumbar disc surgery. Acta Neurochir (Wien) 149: 511-515; discussion 516. doi: https://doi.org/10. 1007/s00701-007-1132-2

47. Bierdrager E, Van Rooij WJ, Sluzewski M (2004) Emergency stenting to control massive bleeding of injured iliac artery following lumbar disk surgery. Neuroradiology 46:404-406. https:// doi.org/10.1007/s00234-004-1198-y

48. Sahinoglu M, Arun O, Orhan A, Nayman A, Calısır A, Böcü Y, Cebeci Y, Duman A, Y1lmaz H, Koktekir E, Karabagli H (2019) Iliac Artery Injury During Lumbar Disc Hernia Surgery. World Neurosurg 125:347-351. https://doi.org/10.1016/j.wneu.2019.02. 025

49. Yip SL, Woo SB, Kwok TK, Mak KH (2011) Nightmare of lumbar diskectomy: aorta laceration. Spine (Phila Pa 1976) 36:E17581760. https://doi.org/10.1097/BRS.0b013e3182194e1c

50. Keskin M, Serin KR, Genc FA, Aksoy M, Yanar F, Kurtoglu M (2013) Iatrogenic major vascular injury during lumbar discectomy: report of three cases. Turk Neurosurg 23:385-388. https:// doi.org/10.5137/1019-5149.Jtn.4930-11.1

51. Vaccaro AR, Kepler CK, Rihn JA, Suzuki H, Ratliff JK, Harrop JS, Morrison WB, Limthongkul W, Albert TJ (2012) Anatomical relationships of the anterior blood vessels to the lower lumbar intervertebral discs: analysis based on magnetic resonance imaging of patients in the prone position. J Bone Joint Surg Am 94:1088-1094. https://doi.org/10.2106/jbjs.K.00671

52. Bozok S, Ilhan G, Destan B, Gokalp O, Gunes T (2013) Approach to the vascular complications of lumbar disc surgery. Vascular 21:79-82. https://doi.org/10.1177/1708538113478727

53. Kwon TW, Sung KB, Cho YP, Kim DK, Ko GY, Yoon HK, Kim GE (2003) Large vessel injury following operation for a herniated lumbar disc. Ann Vasc Surg 17:438-444. https://doi.org/10.1007/ s10016-003-0016-Z

54. Than KD, Wang AC, Rahman SU, Wilson TJ, Valdivia JM, Park P, La Marca F (2011) Complication avoidance and management in anterior lumbar interbody fusion. Neurosurg Focus 31:E6. https:// doi.org/10.3171/2011.7.FOCUS11141

55. Gok M, Aydin E, Guneyli S, Akay A, Cinar C, Oran I (2018) Iatrogenic Vascular Injuries Due to Spinal Surgeries: Endovascular
Perspective. Turk Neurosurg 28:469-473. https://doi.org/10.5137/ 1019-5149.JTN.19286-16.2

56. van Zitteren M, Fan B, Lohle PN, de Nie JC, de Waal MJ, Vriens PW, Heyligers JM (2013) A shift toward endovascular repair for vascular complications in lumbar disc surgery during the last decade. Ann Vasc Surg 27:810-819. https://doi.org/10.1016/j.avsg. 2012.07.019

57. Ozgur BM, Aryan HE, Pimenta L, Taylor WR (2006) Extreme Lateral Interbody Fusion (XLIF): a novel surgical technique for anterior lumbar interbody fusion. Spine J 6:435-443. https://doi. org/10.1016/j.spinee.2005.08.012

58. Silvestre C, Mac-Thiong JM, Hilmi R, Roussouly P (2012) Complications and morbidities of mini-open anterior retroperitoneal lumbar interbody fusion: oblique lumbar interbody fusion in 179 patients. Asian Spine J 6:89-97. https://doi.org/10.4184/asj. 2012.6.2.89

59. Gragnaniello C, Seex K (2016) Anterior to psoas (ATP) fusion of the lumbar spine: evolution of a technique facilitated by changes in equipment. J Spine Surg 2:256-265. https://doi.org/10.21037/ jss.2016.11.02

60. Sandhu HK, Charlton-Ouw KM, Azizzadeh A, Estrera AL, Safi HJ (2013) Spinal screw penetration of the aorta. J Vasc Surg 57:1668-1670. https://doi.org/10.1016/j.jvs.2012.10.087

61. Kueper J, Fantini GA, Walker BR, Aichmair A, Hughes AP (2015) Incidence of vascular complications during lateral lumbar interbody fusion: an examination of the mini-open access technique. Eur Spine J 24:800-809. https://doi.org/10.1007/ s00586-015-3796-2

62. Abe K, Orita S, Mannoji C, Motegi H, Aramomi M, Ishikawa T, Kotani T, Akazawa T, Morinaga T, Fujiyoshi T, Hasue F, Yamagata M, Hashimoto M, Yamauchi T, Eguchi Y, Suzuki M, Hanaoka E, Inage K, Sato J, Fujimoto K, Shiga Y, Kanamoto H, Yamauchi K, Nakamura J, Suzuki T, Hynes RA, Aoki Y, Takahashi K, Ohtori S (2017) Perioperative complications in 155 patients who underwent oblique lateral interbody fusion surgery: perspectives and indications from a retrospective, multicenter survey. Spine (Phila Pa 1976) 42:55-62. https://doi.org/10.1097/ BRS.0000000000001650

63. Zeng ZY, Xu ZW, He DW, Zhao X, Ma WH, Ni WF, Song YX, Zhang JQ, Yu W, Fang XQ, Zhou ZJ, Xu NJ, Huang WJ, Hu ZC, Wu AL, Ji JF, Han JF, Fan SW, Zhao FD, Jin H, Pei F, Fan SY, Sui DX (2018) Complications and prevention strategies of oblique lateral interbody fusion technique. Orthop Surg 10:98-106. https:// doi.org/10.1111/os.12380

64. Härtl R, Alimi M, Abdelatif Boukebir M, Berlin CD, NavarroRamirez R, Arnold PM, Fehlings MG, Mroz TE, Riew KD (2017) Carotid artery injury in anterior cervical spine surgery: multicenter cohort study and literature review. Global Spine J 7:71s75s. https://doi.org/10.1177/2192568216688192

65. Inamasu J, Guiot BH (2005) Iatrogenic carotid artery injury in neurosurgery. Neurosurg Rev 28:239-247; discussion 248. doi: https://doi.org/10.1007/s10143-005-0412-7

66. Pollard ME, Little PW (2002) Changes in carotid artery blood flow during anterior cervical spine surgery. Spine (Phila Pa 1976) 27:152-155. https://doi.org/10.1097/00007632-200201150-00006

67. Neo M, Fujibayashi S, Miyata M, Takemoto M, Nakamura T (2008) Vertebral artery injury during cervical spine surgery: a survey of more than 5600 operations. Spine (Phila Pa 1976) 33:779-785. https://doi.org/10.1097/BRS.0b013e31816957a7

68. Schroeder GD, Hsu WK (2013) Vertebral artery injuries in cervical spine surgery. Surg Neurol Int 4:S362-367. https://doi.org/10. 4103/2152-7806.120777

69. Lunardini DJ, Eskander MS, Even JL, Dunlap JT, Chen AF, Lee JY, Ward TW, Kang JD, Donaldson WF (2014) Vertebral artery 
injuries in cervical spine surgery. Spine J 14:1520-1525. https:// doi.org/10.1016/j.spinee.2013.09.016

70. Molinari RW, Chimenti PC, Molinari R Jr, Gruhn W (2015) Vertebral artery injury during routine posterior cervical exposure: case reports and review of literature. Global Spine J 5:528-532. https://doi.org/10.1055/s-0035-1566225

71. Altunrende EM, Ekin EE (2019) Morphometric analysis of significant vascular structures in posterior disc surgery with computed tomography angiography. Ulus Travma Acil Cerrahi Derg 25:105-110. https://doi.org/10.5505/tjtes.2018.49274

72. Liu L, Liang Y, Zhou Q, Zhang H, Wang H, Li S, Zhao C, Hou T, Liu L (2014) Study on the anatomy of the lumbosacral anterior great vessels pertinent to L5/S1 anterior interbody surgery with computer tomography angiography. Acta Orthop Belg 80:537-543

73. Weiner BK, Walker M, Fraser RD (2001) Vascular anatomy anterior to lumbosacral transitional vertebrae and implications for anterior lumbar interbody fusion. Spine J 1:442-444. https:// doi.org/10.1016/s1529-9430(01)00126-7

74. Millimaggi DF, Norcia VD, Luzzi S, Alfiero T, Galzio RJ, Ricci A (2018) Minimally invasive transforaminal lumbar interbody fusion with percutaneous bilateral pedicle screw fixation for lumbosacral spine degenerative diseases. a retrospective database of 40 consecutive cases and literature review. Turk Neurosurg 28:454-461. https://doi.org/10.5137/1019-5149.Jtn.19479-16.0

75. Hamdan AD, Malek JY, Schermerhorn ML, Aulivola B, Blattman SB, Pomposelli FB Jr (2008) Vascular injury during anterior exposure of the spine. J Vasc Surg 48:650-654. https://doi.org/10. 1016/j.jvs.2008.04.028

76. Ricci A, Di Vitantonio H, De Paulis D, Del Maestro M, Raysi SD, Murrone D, Luzzi S, Galzio RJ (2017) Cortical aneurysms of the middle cerebral artery: a review of the literature. Surg Neurol Int 8:117. https://doi.org/10.4103/sni.sni_50_17

77. Luzzi S, Gragnaniello C, Giotta Lucifero A, Del Maestro M, Galzio R (2020) Surgical management of giant intracranial aneurysms: overall results of a large series. World Neurosurg. https:// doi.org/10.1016/j.wneu.2020.08.004

Publisher's Note Springer Nature remains neutral with regard to jurisdictional claims in published maps and institutional affiliations. 